Volume 6(3), 43-59. http://dx.doi.org/10.18608/jla.2019.63.8

\title{
Moving Forward with Learning Analytics: Expert Views
}

\author{
Rebecca Ferguson ${ }^{1}$, Doug Clow², Dai Griffiths ${ }^{3}$, Andrew Brasher ${ }^{4}$
}

\begin{abstract}
Learning analytics involve the measurement, collection, analysis, and reporting of data about learners and their contexts, in order to understand and optimize learning and the environments in which it occurs. Since emerging as a distinct field in 2011, learning analytics has grown rapidly, and early adopters around the world are developing and deploying these new tools. This paper reports on a study that investigated how the field is likely to develop by 2025 in order to recommend actions to those concerned with the implementation of learning analytics. The study used a Policy Delphi approach, presenting a range of future scenarios to international experts in the field and asking for responses related to the desirability and feasibility of these scenarios, as well as actions that would be required. Responses were received from 103 people from 21 countries. Responses were coded thematically, inter-rater reliability was checked using Cohen's kappa coefficient, and data were recoded if kappa was below 0.6. The seven major themes identified within the data were power, pedagogy, validity, regulation, complexity, ethics, and affect. The paper considers in detail each of these themes and its implications for the implementation of learning analytics.
\end{abstract}

\section{Notes for Practice}

- This paper analyzes responses from around the world and identifies seven factors that must be taken into account when implementing learning analytics: power, pedagogy, validity, regulation, complexity, ethics, and affect.

- Responses revealed widespread unease about how analytics may develop. Bringing people together to engage with and understand the issues will be one way of addressing this problem.

- It is also important for different communities to discuss and understand the value of their personal data and to know how they can be used, developed, and protected.

- Evidence that learning analytics delivers benefits is not yet convincing to experts in the field.

- Major investment of thoughtful effort is required in terms of research agendas and funding, policy and regulation, and developing and informing practice among all those who engage with learning analytics.

\section{Keywords}

Affect, complexity, ethics, implementation, learning analytics, pedagogy, Policy Delphi, power, regulation, validity

Submitted: 06.28.2018 — Accepted: 07.10.2019 — Published: 13.12.2019

Corresponding author ${ }^{1}$ Email: rebecca.ferguson@open.ac.uk Address: IET, The Open University, Walton Hall, Milton Keynes. MK7 6AA, UK. ORCID ID http://orcid.org/0000-0002-8566-8231

${ }^{2}$ Address: IET, The Open University, Walton Hall, Milton Keynes, MK7 6AA, UK. ORCID ID https://orcid.org/0000-0003-3011-1177

${ }^{3}$ Address: Institute for Educational Cybernetics, University of Bolton, Deane Road, Bolton, BL3 5AB, UK ORCID ID https://orcid.org/0000-00026863-2456

${ }^{4}$ Address: IET, The Open University, Walton Hall, Milton Keynes, MK7 6AA, UK. ORCID ID https://orcid.org/0000-0002-6672-4699

\section{Introduction}

The spectacular rise in the quantity and uses of learning data raises large, transnational issues of social practice and regulation (Drachsler \& Greller, 2016). The use of data in education and learning is at a cusp in its development, moving from an interest of a small group of researchers and practitioners to widespread adoption at scale across the entire education sector, affecting schools, higher education, workplace training, and informal learning (Ferguson et al., 2016).

Learning analytics involve the measurement, collection, analysis and reporting of data about learners and their contexts, in order to understand and optimise learning and the environments in which it occurs (Siemens et al., 2011). In other words, the data generated as people engage in learning are used to help improve learning and teaching. 
This is a fast-developing field that has emerged in the last decade and has been taken up worldwide - particularly in Europe, Australia, and North America. It has its roots in business intelligence and data mining and draws on theory and methodologies from disciplines as diverse as education, psychology, philosophy, sociology, linguistics, learning sciences, statistics, artificial intelligence, and computer science (Dawson, Gašević, Siemens, \& Joksimovic, 2014).

The development of learning analytics from these other fields has been attributed to three principal drivers: the increasing availability of large-scale data related to learning and teaching, the increase in online learning, and national concerns about educational performance (Ferguson, 2012).

As well as drivers, there are also barriers to implementation:

...learning analytics offer the possibility of implementing real-time assessment and feedback systems and processes at scale that are focused on improvement of learning, development of self-regulated learning skills, and student success. However, to realize this promise, the necessary shifts in the culture, technological infrastructure, and teaching practices of higher education, from assessment-for-accountability to assessmentfor-learning, cannot be achieved through piecemeal implementation of new tools. (Macfadyen, Dawson, Pardo, \& Gašević, 2014, p. 17)

Educational institutions are complex adaptive systems (Ferguson et al., 2015). As such, they are extremely resistant to change, and strategies for change aimed at only one or a few of their subsystems are unlikely to succeed. Data-based research findings may not be put into practice for many reasons, including decision makers' lack of familiarity with statistical methods, a tendency to base educational decisions on anecdote rather than on research, an institutional focus on technical concerns, or a failure to incorporate analytics within a process of evidence-based decision making (Macfadyen \& Dawson, 2012; McIntosh, 1979).

Learning analytics is also an example of technology-enhanced learning in that the data are generated, analyzed, and presented with the help of a wide range of information technologies. This means that the field of learning analytics must be prepared for and must deal with the rapid rate of change associated with these technologies. "Typically, we find that the doubling time for different measures - price-performance, bandwidth, capacity — of the capability of information technology is about one year" (Kurzweil, 2005, p. 56). The fast pace of change means that if, in 2006, we had developed learning analytics without looking ahead, we would not have planned for learning with and through social networks (Twitter was launched in July 2006), with smartphones (the first iPhone was released in 2007), or learning at scale (the term massive open online course or $M O O C$ was coined in 2008). However, future scanning with the help of experts would have pointed to the opportunities associated with networked learning (Goodyear, Banks, Hodgson, \& McConnell, 2004), mobile learning (Sharples, 2000), and connectivism (Siemens, 2005).

There are therefore two important reasons for looking ahead to consider how learning analytics could develop in the future. First, to implement learning analytics effectively, it must be aligned with the people, practices, and processes that make up an educational system, which is difficult to do retrospectively. Second, learning analytics take time to develop, so their implementation should be aligned with learning and teaching as they are likely to be in the future, rather than as they are now.

The European Commission recognized the need for those involved in learning analytics to work together to consider the development of the field, and to support this effort they funded the Learning Analytics Community Exchange (LACE). This project had three main aims:

- organize a range of activities designed to integrate communities of researchers, practitioners, and providers;

- create a knowledge base of evidence about learning analytics (see Clow, Cross, Ferguson, \& Rienties (2014) for more information); and

- explore plausible futures for learning analytics.

The work reported here addressed the third of these aims and was designed to answer the question, "What are the main factors that must be taken into account when implementing learning analytics during the coming decade?" To answer this question, the study systematically solicited and collated informed judgments on learning analytics from experts and used these to identify the areas that these experts judged most important to the successful implementation of learning analytics in the next 10 years.

\section{Materials and Methods}

The study reported here involved experts from across sectors, drawing on the community engagement activities of the project, 
giving an unprecedented breadth of perspective to the study. The study was open to all members of the project communities, who were all professionally active in learning analytics, as researchers, teachers, developers, or providers. The scope included all aspects of education, including schools, higher education, and the workplace. The study was also opened to members of the public who were sufficiently interested in learning analytics to participate in the online activities. This breadth gives more validity to the agenda it sets out, enabling researchers, practitioners, and policymakers to make well-informed and wellgrounded decisions. There is no previous work exploring the future of learning analytics that draws on such a wide network of international experts. Existing reports on pedagogic futures draw on a narrower range of expert authors and are not peer reviewed as research outputs (Adams Becker, Freeman, Giesinger Hall, Cummins, \& Yuhnke, 2016; Johnson et al., 2016; Sharples et al., 2016). The experts surveyed in this study bring together expertise in both the technical aspects of analytics and the wider social and pedagogical contexts and educational theory. This gives the work a thorough, practical grounding. Drawing on a range of experts distinguishes this work from other expert opinion pieces in the field that seek to set out agendas and conceptualize the field but are grounded chiefly in the authors' perspectives (for example, Campbell, DeBlois, \& Oblinger, 2007; Long \& Siemens, 2011), rather than the wide range of opinion represented in this work.

To elicit expert opinion in this area, the study used the Policy Delphi method. This method, developed by Turoff in the 1970s, is a significant variation on the Delphi method (Dalkey, 1969). A Policy Delphi is designed to generate the strongest possible opposing views on a major policy issue (Linstone \& Turoff, 2002). Turoff argued that "the decision maker is not interested in having a group generate his decision; but rather, have an informed group present all the options and supporting evidence for his consideration" (Turoff, 2002, p. 80). A Policy Delphi is different from a survey in both its objectives and its method. We follow Turoff, who states that "a Policy Delphi should serve any one or any combination of the following objectives:

- To ensure that all possible options have been put on the table for consideration

- To estimate the impact and consequences of any particular option

- To examine and estimate the acceptability of any particular option.” (Turoff, 1970, p. 494)

Regarding the method, Turoff (2002, p. 84) sets out six stages (in italics below), which we carried out with adaptations appropriate to the context of a community activity within a project:

(1) Formulating the issues. This was done in the set-up period when members of the project consortium jointly discussed and agreed on the provocations (visions) to be presented to participants.

(2) Exposing the options. Given the issue, what are the policy options available? This was done by asking participants what would be necessary to make one of the provocations turn into a reality.

(3) Determining initial positions on the issues. Which are the ones everyone already agrees upon, and which are the unimportant ones to be discarded? Which are the ones exhibiting disagreement among the respondents? The project team achieved this by analyzing the Likert-scale results.

(4) Exploring and obtaining the reasons for disagreements. What underlying assumptions, views, or facts are being used by the individuals to support their respective positions? This was achieved by thematically analyzing free-text contributions by the respondents.

(5) Evaluating the underlying reasons. How does the group view the separate arguments used to defend various positions, and how do they compare to one another on a relative basis? Again, this was achieved by thematic analysis of the data.

(6) Re-evaluating the options. Re-evaluation is based on the views of the underlying "evidence" and the assessment of its relevance to each position taken. This is a process for the community, with which we have discussed our findings via the project website and via numerous presentations and workshops. Indeed, the present paper is offered as a means of achieving this re-evaluation.

This study was reviewed and approved by the Human Research Ethics Committee of The Open University.

\section{Data Collection}

The first phase of the Policy Delphi study developed a series of visions of learning analytics in 2025 that could be used as provocations to prompt thoughtful responses. The core project team consisted of 12 principal and co-investigators, drawn from a consortium of nine institutions in six different countries, in the school, higher education, and workplace sectors. It was decided that this was a suitable set of experts to develop the initial set of visions because the peer assessments sought by the 
European Commission at the funding stage had validated the capacity of the team to address learning analytics issues at a European level. Following a matrix analysis, eight of the visions proposed by this group were selected because they were cutting edge but still realistic; likely to provoke strong reactions; relevant to stakeholders; and concerned with relevant areas, including technology, pedagogy, privacy, and ethics.

Table 1 gives the titles of the eight visions; the full text of around 100 words for each vision is available in Griffiths, Brasher, Clow, Ferguson, and Yuan (2016). The visions explored futures in which increasing amounts of data relating to learning and teaching are available $(1,2)$, data control is a priority (4), open approaches to analytics are in place (5), and learning analytics have been implemented in various ways (6-8), as well as one scenario in which learning analytics have not been taken up (3).

Table 1. Titles of the Visions of the Future of Learning Analytics Used in the Policy Delphi

\begin{tabular}{ll}
\hline & Vision Title \\
\hline 1 & In 2025, classrooms monitor the physical environment to support learning and teaching \\
2 & In 2025, personal data tracking supports learning. \\
3 & In 2025, analytics are rarely used in education. \\
4 & In 2025, individuals control their own data. \\
5 & In 2025, open systems for learning analytics are widely adopted. \\
6 & In 2025, learning analytics systems are essential tools of educational management. \\
7 & In 2025, most teaching is delegated to computers. \\
8 & In 2025, analytics support self-directed autonomous learning. \\
\hline
\end{tabular}

The second phase of the study used the online tool SurveyMonkey to survey two groups. First, experts were designated by the project work packages dealing with Schools, Workplace and Higher Education, paying attention to the three principal contributing discourses of learning analytics in the project (technology, privacy and ethics, and pedagogy). The project's associate partners were all included in this expert group. Second, volunteers were solicited in publicity generated on the project website and the project newsletter. A total of 193 designated experts were sent emails with direct links to the survey, which enabled the team to keep track of the proportion of responses from invited experts, and to contrast their input with that of the volunteers. It should be noted that the volunteers were also likely to have a high degree of expertise in learning analytics, given their engagement with project communications.

For each vision, participants were asked to use a Likert scale to respond to two questions:

1. How desirable is this vision? Please give your answer on a scale from 1 to 4 .

2. How feasible is this vision? Please give your answer on a scale from 1 to 4 .

For both questions, "I do not feel qualified to respond" was also a possible response. Respondents were also invited to make free-text comments to elaborate on their Likert scale responses.

A free text field was provided for respondents with the heading "In the light of the score you have given for desirable - - - - undesirable, what actions do you think should be taken? For example there may be legal, policy, technical or other developments which you think are needed to make this vision a reality, or to prevent it happening. Please describe the initiatives which are necessary, and who should take them."

Before being presented with the survey, both the purpose of the study and how their data would be used were fully explained to all participants. This was a voluntary, opt-in study, and written response was the method of obtaining consent from participants. Participants were also offered the opportunity to state that they did not want their free-text input to be quoted. Because reading and commenting on eight 100 -word visions would be a time-consuming process, visions were presented to participants in a random order. Each of them was asked to respond to at least three visions (mean response rate was 3.6 visions per participant), and, after each vision, participants were asked if they would be willing to respond to another.

The survey was only produced in English. This was because the researchers' experience with the international Society for Learning Analytics Research (solaresearch.org), the project, and the main international learning analytics conference series (Learning Analytics and Knowledge - LAK) suggested that the majority of work in this field is currently carried out in English (Ferguson et al., 2015). Email addresses of respondents indicate that they were based in 21 countries in Asia, Australasia, Europe, and North America. As there was relatively little learning analytics work in progress on other continents, this was judged to be a wide enough sample to provide a generalizable answer to the research question. 
Following the direct mailing of survey links to invited experts and the publication of a generic participation link on the project website and newsletters, 134 people started the process of answering the questionnaire, 68 of whom responded to an invited expert link, and 66 of whom used an open link made available by the project. Of these respondents, 103 responded to at least one vision. The number of complete responses to visions was 487 , an average of 3.6 per respondent. No pattern was discerned in the profile of those respondents who did not respond to any visions.

To monitor expert coverage of different sectors of education and different topic areas, respondents were asked two questions about themselves, as shown in Table 2. Respondents could rate their experience in more than one area, as even experts are unlikely to have detailed knowledge of the whole of learning analytics. Information on expertise was not used to reject responses but rather to identify areas in which respondents had some degree of expertise, as an aid to interpretation of the data.

Table 2. Responses to Questions about Areas of Expertise

\begin{tabular}{|c|c|}
\hline How well informed are you about learning analytics in terms of & $\begin{array}{l}\text { Respondents rating } \\
\text { themselves } 3 \text { or } 4 \text { on } \\
\text { a scale from } 1 \text { to } 4\end{array}$ \\
\hline Learning technology? & 45 \\
\hline Analytics and machine learning? & 33 \\
\hline Ethical issues? & 24 \\
\hline Privacy issues? & 25 \\
\hline Pedagogy and professional practice? & 41 \\
\hline $\begin{array}{l}\text { Which sectors of education have you worked in? Please tick all that } \\
\text { apply. }\end{array}$ & $\begin{array}{l}\text { Respondents with } \\
\text { experience in each } \\
\text { sector }\end{array}$ \\
\hline Schools & 36 \\
\hline Workplace & 29 \\
\hline Higher Education & 115 \\
\hline
\end{tabular}

The project, and this study, were open to all sectors. However, the great majority of respondents had experience in higher education. This reflects the important role played by the sector in the development of learning analytics systems and in the production of relevant research. It may, however, also be suggested that higher education has a greater culture of open innovation than commercial providers of educational services and technology, and therefore a greater willingness to engage with projects such as this one. This would explain the relatively low number of workplace participants.

Respondents were then asked to assess each vision that they viewed in terms of its feasibility, its desirability, and the steps that would be required to make it a reality. Data gathered for each vision included both a Likert scale and free text. Standard questions were asked for each vision, with the option to select "I do not feel qualified to respond" instead of selecting an answer on a $1-4$ scale:

- How desirable is this vision? Please give your answer on a scale from 1 to 4.

- If you selected an answer from 1 to 4, please tell us about the reasons for your answer.

- How feasible is this vision? Please give your answer on a scale from 1 to 4.

- If you selected an answer from 1 to 4 , please tell us about the reasons for your answer.

- In the light of the score you have given for desirable/undesirable, what actions do you think should be taken? For example there may be legal, policy, technical or other developments which you think are needed to make this vision a reality, or to prevent it happening. Please describe the initiatives which are necessary, and who should take them (free text). 


\section{Data Collection}

\subsection{Likert Scale Data}

The eight visions were developed as an instrument to provoke discussion of underlying themes and issues, and in this paper we focus our analysis on determining the underlying themes that emerged, rather than on particular visions. Before moving to qualitative analysis, we examined the Likert scale responses relating to desirability and feasibility of visions (Griffiths et al., 2016) to assess whether we had achieved the Policy Delphi aim of soliciting a wide variety of expert views.

Figure 1 shows the average for each Likert scale and draws attention to those visions where there was a disparity between desirability and feasibility. In this representation, a unanimous minimum negative response of "not desirable" or "not feasible" would be represented as $0 \%$, while a unanimous maximum positive response would be represented as $100 \%$. Intermediate values are weighted accordingly.

\section{$100 \%$ Positive}
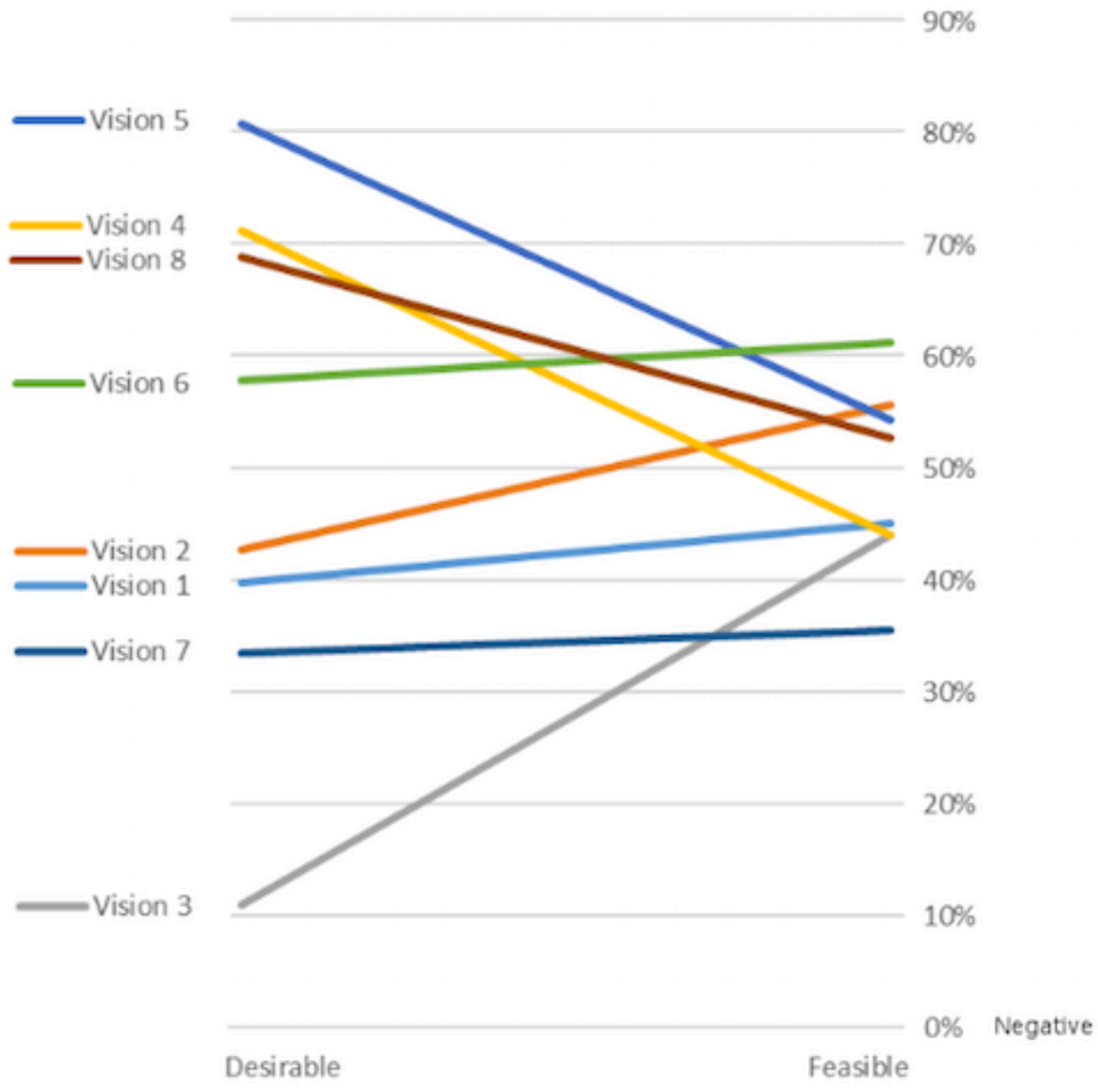

Figure 1. Attitudes to desirability and feasibility (Griffiths et al., 2016, p. 42)

Figure 1 shows the wide variation in respondents' views of the desirability of the visions. There is much greater agreement on their feasibility. This convergence of views expressed on feasibility suggests that there is, to some extent, a shared understanding of the capabilities of the technologies available to implement learning analytics. On the other hand, the wide range of views on desirability suggests a wide disparity of views regarding the purposes for which these technologies should be used.

For some visions, there was a large discrepancy between desirability and feasibility.

- Three visions — vision 1 (physical environment), vision 6 (essential tools), and vision 7 (delegation of teaching) are seen as similar in their desirability and feasibility.

- Two visions - vision 2 (personal data tracking) and vision 8 (autonomous learning) - have a substantial degree of 
discrepancy between desirability and feasibility.

- For three visions - vision 3 (rarely used), vision 4 (data control), and vision 5 (open systems) - there is a very strong contrast between desirability and feasibility.

In all three cases where there is a large disparity, the respondents indicate that this is due to a mismatch between technical capability, on the one hand, and social and political implications, on the other. In the case of vision 3, the concern is that social, political, and pedagogic factors will result in learning analytics being abandoned, even though this is an undesirable outcome. In the case of visions 5 and 6 , the concern is that initiatives enabling learning analytics to make a positive contribution to education and society will be prevented by social and political factors. These results warn us against thinking of the future of learning analytics solely in terms of the technical concerns of analytics methods and pedagogical applications.

The wide range of views and opinions identified by analysis of the Likert-scale responses indicated that we had successfully met our Policy Delphi objective of collecting a wide range of expert views. Therefore, the full set of survey data was downloaded from SurveyMonkey into Excel as comma-separated values. The free-text survey responses included 29,426 words. Data from respondents who did not want to be quoted were highlighted to ensure that their responses could be analyzed but would not appear in print. Data were organized using R scripts (for example, to present data for each vision on a separate spreadsheet).

Thematic analysis of the free-text responses was carried out. When using this form of analysis, each theme "captures something important about the data in relation to the research question, and represents some level of patterned response or meaning within the data set" (Braun \& Clarke, 2006, p. 82). In this case, the analysis was used to identify themes that represent the main factors that must be taken into account when implementing learning analytics during the coming decade.

A team of four researchers (the authors of this paper) worked together to identify and code the themes within the data. In a full-day working session, they first worked together to derive codes from the free-text responses for the first vision and then reviewed the resulting codes and merged them where appropriate. Once codes had been agreed on, the researchers worked individually to code the remaining data - discussing any doubtful cases. Coding was non-exclusive, so each text could be associated with more than one theme.

To check inter-rater reliability, a third of the data for each vision was re-coded by a team of two researchers working collaboratively. Data relating to the first vision were omitted from this process, as four researchers had already agreed on its coding. Cohen's kappa was then calculated for the re-coded data, comparing the two sets of coding (Cohen, 1960). Kappa of 0.61 and above was taken to represent substantial agreement (Landis \& Koch, 1977). In four cases, the value for kappa was below 0.61 and, in these cases, two researchers working collaboratively re-coded all data for that vision.

\subsection{Thematic Data}

Thirteen themes were derived from the data, which included 1,095 textual responses (see Table 3).

Table 3. Responses to Questions about Areas of Expertise $(N=1,095)$

\begin{tabular}{clrc}
\hline No. & Theme & $\begin{array}{c}\text { Count of } \\
\text { coding }\end{array}$ & $\begin{array}{c}\text { \%o of } \\
\text { responses }\end{array}$ \\
\hline 1 & Power & 315 & $29 \%$ \\
2 & Pedagogy & 313 & $29 \%$ \\
3 & Validity & 187 & $17 \%$ \\
4 & Regulation & 173 & $16 \%$ \\
5 & Experience & 171 & $16 \%$ \\
6 & Complexity & 145 & $13 \%$ \\
7 & Ethics & 145 & $13 \%$ \\
8 & Affect & 144 & $13 \%$ \\
9 & Costs & 110 & $10 \%$ \\
10 & Privacy & 107 & $10 \%$ \\
11 & Temporal & 106 & $10 \%$ \\
12 & Alienation & 89 & $8 \%$ \\
13 & Standards & 77 & $7 \%$ \\
\hline
\end{tabular}


Of these, the first eight were judged to be the most significant themes due to the number of times they had appeared in the data. One of these, experience, is not discussed further here, because a large majority of comments coded in this way related to participants' experience of completing the survey, and few related to the future of learning analytics.

The seven most significant themes are described below in an order suggested by the text of the data, highlighting related themes. Minor themes are described briefly in a final subsection. As this was a Policy Delphi study, designed to elicit the widest possible range of expert opinion, the number of times specific points were raised is not discussed. Quotations are given verbatim, without alteration or correction to spelling, grammar, or punctuation, except in cases where capitalization has been changed to fit the broader sentence structure or where meaning is unclear, in which case square brackets indicate the alteration. In each case, a four-digit number enclosed in square brackets is used to identify individual respondents. This number is derived from the 10-digit reference code automatically assigned to responses by SurveyMonkey.

\subsubsection{Power}

The theme of power overlaps with that of ethics in the area of data control. The issue in the case of power is not how data should be controlled and used to do no harm, but who should have control of it and why. Issues of power also influence who controls the learning process, who sets goals for learners and teachers, who controls the analytics, and who understands the analytic process. Respondents considered when control should be in individual hands, when it should rest with the institution, when commercial companies have a role to play, and when national and international bodies should take the lead.

The individual or organization with control of data potentially also has the power to make a range of decisions about the learning and teaching process and about how learners and teachers should act. This is a power that could be misused or abused, possibilities that concerned some respondents. [5297] observed that "if tracking and monitoring are used to foster and support education and learning, it might be desirable. If it is used to monitor and control and to enforce power it is not desirable."

In practice, control of data is distributed between many stakeholders, for many purposes. Educational data are already used at a national level, and [2692] noted that "It's unlikely that governments or institutions will relinquish their control over learner data." However, if governments controlled all data, then educational institutions would lose the power to make informed choices. "I think it is vital that educational establishments have control over the methods and tools that they use with their students" [9792]. Schools and universities use data about students and teachers to exercise their own power — "there will be times when the institution needs to be able to decide where to share information about progress, attendance and exam results, for example, as part of a disciplinary process" [7076].

External bodies, particularly commercial companies such as learning management system (LMS) providers, are also likely to have access to analytic data. Respondents had concerns about this: data may be handed over to companies without sufficient consideration of how the data might be used in an intrusive way to monitor behaviour and activities. Respondents were also worried that commercial power could be used to limit data access. "Experience suggests that money talks and the large international companies that supply education succeed by keeping some of the analytics and data generated hidden behind intellectual property barriers" [4820].

At a more individual level, several stakeholders could take control of data. One obvious choice is the teacher: "One of the purposes of LA is to empower the teachers to provide better learning for the individual learners. To know earlier what the learners problems are and to be able to address those problems" [5297]. However, there are potential problems no matter who is in control:

I am not sure who *should* make use of such data: with care and education, it might be of direct value to learners. Teachers are likely better placed to make use of the data, but it is all too easy for it to be a tool for asserting power. It is even worse to put that control in the hands of system designers and programmers, thus embedding their assumptions and beliefs (or, just as likely, making use of whatever turns out to be easiest to program and capture). [7473]

Control over the data is inextricably bound up with the need for knowledge to make use of the data. [5140] proposed that "every single person must be enabled to decide who, when and how to proceed with the data." In order for that to be possible, or even partly possible, learners and other stakeholders "need to be educated to deal properly with the choices concerned" [7936]. This does not necessarily require technical training, but stakeholders do need to be able to ask the right questions. "Although not all consumers of these services will have the skill necessary to understand the computer science and computation, it is necessary that they have the access to question the processes and assumptions under which the data is input, massaged, and output" [6616].

In order to control the use of data and analytics, there were several suggestions for boosting existing power structures. [3345] felt that "institutions should increase their 'critical mass' in the decision tables on standards, transparently imposing a 
set of standards to all the companies that want to sell learning products in that country." "What and how data is shared could be agreed in democratic processes within the institution and its stakeholders" [2785].

An alternative would be to work on a larger scale because "we need institutions and mechanisms that are independent and act on behalf of students and teachers" [1933]. One option would be to debate issues at a national or international level. Another would be to set up a new government authority that could act as "a trusted clearing house for data and analytics" [8581].

Recent initiatives in the area include a report from the National Academy of Education (2017) in the United States, discussing the control of data and of learning analytics processes. In Europe, the issue is dominated by the GDPR regulation as discussed, for example, by Cormack (2016) in relation to the UK, and by Engelfriet, Manderveld, \& Jeunink (2017) in relation to the Netherlands.

\subsubsection{Pedagogy}

"It all starts with the pedagogical perspective" [2804]. Pedagogy is taken here to mean a theorized approach to teaching and learning. This theme encompassed a series of broad issues: why we are educating people, how people learn, the pedagogic outcomes we are trying to achieve, and how we can measure those outcomes. Respondents were also interested in how to train teachers to make effective use of analytics.

Many respondents linked their view of learning analytics to their understanding of what education is for: change, growth, transformation, and the development of society. "Our society needs to ask itself where are the citizens educated and who is responsible of that education" [8698]. "We have a social duty to facilitate and provide opportunities for learners to achieve their full potential" [3462]. "Education overcomes historical injustices" [6064].

They also outlined their understanding of what learning is: "a dynamic process that is not linear" [0650], "a human, socially embedded, communal activity" [7473], "contextual, depends on personal capabilities" [5095], and "an essentially social activity which relies on mutual trust and confidence" [0649]. "Education is about collaboration, about human interaction, about creativity, about innovation and about spontaneity" [5297].

Respondents were clear that learning analytics need to take these different aspects into account and should not treat education as a process of imparting information to individuals. "What is needed is support for reflection, discussion and debate on the purpose of it all, especially to curb the excesses of those that see learning as something teachers do to students. We need to nurture rich, reflective communities in both teaching and learning" [7473].

Some respondents were also worried that learning analytics would be used to remove essential but challenging elements of the learning process, believing them to be dispensable. "Learning is not only about success is about learning from failure" [3614] and "there is a time for learners to be confronted in order for transformation and growth to occur" [3462].

It is clearly difficult to express a dynamic process of transformation, innovation, and spontaneity in terms of measurable items. Some respondents felt that learning is not open to observation in this way and that it is difficult to define success in measurable terms that hold true in different contexts. Others felt that it is dangerous to equate learning with measurable outcomes because this would "reduce learning to the acquisition of those skills that can be measured and advised by the sensors and apps" [8698]. However, others referred to existing or ongoing research that shows relationships between activities and progress toward learning goals or changes in learning behaviour.

An idea strongly expressed by many was that "we need a human teacher to guide and scaffold us" [6818] and that human interaction is a crucial part of the learning process. Nevertheless, there were criticisms of approaches to teaching that are not based on evidence.

In order to embed analytics effectively within teaching practice, many respondents suggested continuing professional development. They felt that this was needed in order to enable teachers to make use of these new tools, to interpret the additional information appropriately, and to use the data in meaningful ways.

Readers interested in following up on this issue are directed to a resource developed by the project, the LACE Evidence $\mathrm{Hub}$ (http://evidence.laceproject.eu/), which is designed to assist in evidence-based decisions on learning analytics in learning and teaching. The practitioner tracks of the LAK conference series provide a rich picture of developing pedagogic work with learning analytics. There are also valuable papers on current work in a special issue of Interaction Design and Architecture $(s)$ devoted to Connecting Learning Design and Learning Analytics (Hernández Leo, Rodriguez-Triana, Inventado, \& Mor, 2017).

\subsubsection{Validity}

An area that was touched upon under the theme of regulation was quality assurance of analytics. A key element of quality assurance in this context is validity. How can we be sure that the recommendations and results produced by learning analytics are valid, reliable, and generalizable? This is important to establish, because the underlying algorithms are rarely open to scrutiny. Even when the algorithms are freely available, learners and teachers are unlikely to have either the time or the experience to check their validity. Respondents agreed that more work is needed in this area. 
we are still in the 'proof of concept' phase. Much has been hypothesized about potential. Some good research has supported some predictive power; other research is less clear. Very little credible research has demonstrated any real large-scale benefits to learners or institutions. [2775]

Validating analytics would involve clearly linking behaviours and measurable outcomes with pedagogy and with learning benefits and employing an appropriate and robust scientific method. "The use of LA applications in real practice has be conscious of the limitations of any analysis, and apply them in a way that is coherent with the limitations of the approach" [8698]. Validation also covers selecting and representing data carefully, applying an appropriate conceptual framework, and taking context into account when reporting results.

Research in this space should be tied to pedagogical outcomes. If certain monitoring provides tangible learning benefits, than it should be explored further. If we are just collecting data because we can, and then trying to fit it to arbitrary behavioural outcomes, then the work is futile. [2625]

This work would need to build on previous work in learning analytics and in other fields and would involve scientific cooperation and discussion to share and build on results. "Key researchers in learning analytics should provide their resources to orchestrate all those single project initiatives on a global scale" [5140]. Reviewers would need to ensure that there was no hype or misrepresentation of results, and that no conflict of interest was involved. "There will always be some greedy gurus trying to sell you something based on poor research and spurious statistics" [4820]. Overall, the research would build into a reliable evidence base.

If we hope to convince leaders, institutions and sceptics of the value of our models and systems, we MUST be willing to unpack the algorithms. Academics are extremely unlikely to accept 'black box' predictive tools it goes against the very principles of critical thought. [2775]

Even then, educators would need training to be able to question the analytic process and its assumptions, to avoid analytics that have not been validated, and to make use of the analytics in a valid way. "Lots of professional learning would be required to ensure that all this information is interpreted and used appropriately" [4352].

Readers interested in this theme are again directed to the LACE Evidence Hub (http://evidence.laceproject.eu/) for resources discussing validity. The issue of the openness of models and systems has been championed by the Open Learning Analytics initiative of the Society for Learning Analytics Research (Siemens et al., 2011) and by the Apereo Foundation (Apereo, 2016). ADL also supports the development of a suite of open-source applications with transparent functionality that work with the xAPI specification (ADL, 2018).

\subsubsection{Regulation}

Issues of power and also of ethics are bound up with regulation of the field and how this regulation should be developed and enforced. Key areas for regulation were seen to be the protection, ownership, and storage of data and the development of standards. Respondents also considered that policy would need to be developed in the areas of education, privacy, ethics, and assessment.

Some saw control of personal data as a fundamental human right that should be dealt with by the United Nations. "It must be handled as a human right in the 21 st century that every single person should have the power to decide, when + how + for what purpose + for which timeframe $+\ldots$ his/her personal data can/cannot be used" [5140]. This would take the issue out of the hands of national government, to be replaced by a "Legal framework governed by an international authority. Perhaps key concepts included in the fundamental human rights declaration" [0650].

Most respondents who referred to regulation, though, saw this as something that would take place at a national or institutional level.

From organisational point of view, one key of implementing learning analytics relates to ethical and privacy issues, in terms of the creation of rules and regulations for using sensitive personal data. Processing and using such data must be clear and communicated in advance. There could be a need of governmental control that such institutional rules and regulations must exist and should meet certain criteria. [5140]

Several models for policy were suggested, drawing on previous legislation in the areas of privacy, child protection, data protection, consumer protection, and the use of personal data in medical research 
In the area of standards and interoperability, the non-profit member organization IMS Global Learning Consortium was regarded by some as the organization to take this work forward. [6064] suggested that there was a need to "work with IMS Global for an interoperability structure that empowers students," recommended "institutional engagement with IMS Global's work on competency-based education and Caliper [an interoperability standard]," and identified a need to "partner with IMS Global to define supportive specifications and conformance tests."

Several respondents proposed forms of organization or infrastructure that could help to move analytics forward. These included the proposal from [8581] for "a new government authority that acts as a trusted clearing house for data and analytics" and the suggestion by [5140] of a "coordinating board."

Readers interested in this theme are directed to the GDPR rules for the protection of personal data (European Parliament and Council, 2016). Important enabling interoperability specifications include Caliper (IMS Global Learning Consortium, 2018) and xAPI (ADL, 2017); an open specification for learning analytics interoperability is available at http://www.laceproject.eu/deliverables/d7-4-learning-analytics-interoperability-requirements-specifications-and-adoption/.

The issues have been discussed in a global context in a paper by project partners following the close of the project (Hoel, Griffiths, \& Chen, 2017).

\subsubsection{Complexity}

Respondents saw learning analytics as complicated in many ways. Major complexities include the problem of how to understand the internal process of learning through measurement of external actions, the range of stakeholders to be engaged, and the problems inherent in processing enormous amounts of data from diverse sources. There was widespread agreement that more work is needed, but also optimism that the learning analytics community can solve these problems together by building on existing work.

Respondents viewed the measurement of learning as both complex and problematic. [6446] suggested that "work should focus on understanding how the learning process really works," developing a nuanced model that applies to individual learners rather than to learners in general. [4762] proposed the development of a new proxy for learning - "correlation between what somebody learns and the visual perception of how s/he is learning." Others observed that learning does not take place only in the classroom, so learning analytics cannot only be designed for closely controlled environments but need to take into account the wider experience of learners.

This means that "It demands enormous quantity of data to monitor individual learning" [2428]. However, many respondents were optimistic that data problems can be dealt with, pointing to existing work and experience. As [0649] noted, it is "hard to believe that there will be enough processing power to do this, but I guess people always say that when something is ten years away." Smart houses, wearable technology, the Internet of Things, and facial recognition are increasingly part of everyday life, so the data collection and data crunching necessary for learning analytics should not prove to be impossible. "There exist already tools that monitor what is happening in blended learning scenarios and provide teachers — and learners — advice, in different ways" [8698]

Several respondents put forward ideas akin to "sector-wide ownership of this issue" [1933]. These include reflective communities and widespread alliances involving national organizations, ministries of education, and educational institutions. These proposals indicate how many stakeholders are involved in the learning analytics process. Although attention focuses on learners and educators, other groups involved are policymakers, standards organizations, teacher trainers, researchers, university managers, companies that are developing analytical tools and implementing LMSs, educational institutions, workplace learners, user communities, and society as a whole. Large-scale implementation of learning analytics will need to take all of these groups into account. It will also need to take into account issues that affect all of these groups, such as ethics.

Readers concerned about the complexity of implementation are directed to the efforts to develop frameworks and infrastructure, such as the Apereo Foundation mentioned above and the Jisc Learning Analytics service (Jisc, n.d.). Jisc has developed shared descriptions of learning activities in collaboration with communities of users using xAPI (Jiscdev, n.d.), while IMS Caliper (IMS Global Learning Consortium, 2018) has done something similar within a closed consortium. The Society for Learning Analytics Research (SoLAR) and its annual LAK conferences constitute an essential forum for dealing with the challenges of implementation. The SHEILA project, which includes a number of the project partners, has been working with European universities to develop a policy framework to facilitate the adoption of learning analytics by institutions (Tsai, Moreno-Marcos, Tammets, Kollom, \& Gašević, 2018).

\subsubsection{Ethics}

Ethics is taken here to refer to "systematizing, defending, and recommending concepts of right and wrong conduct" (Ferguson, Hoel, Scheffel, \& Drachsler, 2016, p. 7). It is therefore distinct from privacy, which is covered below in the section on minor themes. There was widespread agreement among respondents that there needs to be some form of regulation in this area and that control of data has ethical implications. In parallel with the need for regulation (covered separately below), there is also a 
need for awareness of how data are being used and how analytics function. Respondents were also concerned that a focus on data as a valuable commodity could result in unethical practices.

Although ethical issues are often presented as restrictive, several respondents stressed their positive side and the benefits for society that learning analytics may bring. [7514] noted that "the ethical issue is something that is needed. The people that are involved in this process need to be aware of the benefits that analytics can bring to education." [5199] wanted policy to "strengthen the individual's right to education," [6818] highlighted equality — "everybody should gain access to these systems for improving educational outcomes," and [3462] was clear that "we have a social duty to facilitate and provide opportunities for learners to achieve their full potential."

Many respondents were vague about what the ethical concerns associated with learning analytics actually are, while stressing the need for an ethics policy, norms of good practice, or "a robust ethical framework, supported by legislation" [7076]. Potential problems specifically mentioned include gaming the system, untrustworthy analytics, the creation of a two-tier educational system where only some have access to valid analytics, and the possibility that we could be "typecasting/stereotyping and even discriminating against certain individuals or groups on the basis of data" [3462].

Data ownership and control were seen as important issues. "The key is to establish the notion that each of us own our own data: the companies do not. If this can be recognized, it moves the needle from our data being co-opted and sold back to us to a vision where the ultimate good can be achieved" [6616].

However, control alone is not sufficient if people do not understand how and why they should exercise that control. "It is essential that people are better equipped to understand their rights and how to control how it is used. Putting the owners of the data more central to the process makes it easier for people to accept its value" [7137].

In practical terms, that might involve the use of "clear and understood ethical guidelines" [4361]. An alternative approach would be to move the responsibility to the institution, with governments specifying that "institutional rules and regulations must exist and should meet certain criteria" [5140]. This seems possible, but [5140] also noted that if a government regulates the use of personal data, "this would influence the independency of Universities in teaching and research."

Giving individuals control of their own data would raise administrative problems, as well as requiring training for those individuals. An ability to opt out could also reduce the efficacy of analytics for others, and [7792] argued that this should not be possible:

In educational research it is crucial to include data from all kinds of students. When parents consent is required, we get considerable data losses from i) weak students (parents don't want to 'give away' information for children they hold weak) ii) students with low-educated parents (who can't read instructions, may be more skeptical about society, school etc., who are more likely to just say 'no' to have less work, etc.). We loose data from the children that we most of all want to support by developing educational tools and the educational system. What would even 'selected' data mean? As long as the data is anonymous data should be allowed to be used in these kinds of applications without any consent. [7792]

As well as control of data, the value of data was also a concern. Respondents worried that student data could be sold to third parties, and that the "potential for misuse by e.g., insurance companies is very high" [1643]. There was also "the threat of profit-motivated businesses trying to take control of this information, 'de-commonising' it and selling it back to the individuals concerned" [7936].

Readers concerned with the ethical aspects of learning analytics are directed to work done in the project on a checklist for trusted learning analytics (Drachsler \& Greller, 2016) and the Ethics and Privacy in Learning Analytics workshop series (LACE, n.d.). Prinsloo \& Slade (2017) provide an overview of ethical issues with learning analytics, and recent initiatives to address them, while a report from the Association of Research Libraries (Perry et al., 2018) examines ethical concerns about the use of library data in learning analytics.

\subsubsection{Affect}

Affect is taken here to refer to the experience of feeling or emotion. Respondents identified two main affective issues associated with learning analytics. The first was a need to bear in mind what it is that engages and motivates learners and teachers. The second was a feeling of discomfort or unease about various aspects of learning analytics.

Eleven responses referred to "the importance of the motivation as a critical component in learning" [5095]. Some were not convinced that this component could be operationalized and measured: "the real fuel of Learning is motivation and volition, which you cannot capture with external sensors" [1301]. Others dealt with how learning analytics could increase or decrease motivation. Some felt that many students do not have sufficient intrinsic motivation to engage them for long if they are left to work with the support of data tracking and learning analytics rather than teachers. Others felt that the personalization of learning 
made possible by learning analytics could increase both motivation and interest in learning and that "autonomy begets engagement, motivation, persistence, relevance" [0989].

Many of the possible futures for learning analytics provoked discomfort or unease. Respondents were unhappy about the release of data, saw some forms of data collection as intrusive, and worried about being monitored. For example, two respondents described Vision 1 as "a bit scary" because, as [8698] notes, "all our movements (even the unconscious ones) are being supervised by the technology." This concern is closely related to the minor theme of alienation (see the section on minor themes below).

These feelings of unease were related to a lack of trust in the people developing and deploying the analytics. [0649] describes learning as "an essentially social activity which relies on mutual trust and confidence," and [5297] identifies a need for "complete trust between the 'owner' of the data, their guardians and the systems processing and managing the data." Both learners and teachers need to be able to trust the people and systems that control their data, as well as the algorithms that are used to guide decisions about learning.

The finding that there was substantial discomfort and unease around learning analytics led the authors to raise the issue with the Society for Learning Analytics Research and the LAK program chairs. One response to this was the invitation to Neil Selwyn as a keynote at LAK '18, where he explored some of these feelings of discomfort and how they arise (see also Essa, 2019; Ferguson, 2019; Prinsloo, 2019; Rosé, 2019; and Selwyn, 2019, in an Invited Dialogue Special Section in the current issue).

\subsubsection{Minor Themes}

In addition to the seven major themes reported in the previous subsections, analysis identified six other themes in the data. (As explained above, experience is not discussed in detail here.) The other five themes to emerge were standards, temporality, cost, alienation, and privacy.

The theme of privacy was closely related to ethics and regulation and covered similar areas. The theme of standards dealt with areas that were also covered under the headings of regulation and validity. The theme of temporality was more diverse but mainly looked at experience, predictions, and the time needed for implementation.

The theme of costs was related to two main concerns. The first was related to the value of data. As [6446] noted, "Humans need to understand that their data is an equal to a currency." These issues overlapped with those covered by power, ethics, and regulation. The second concern was related to the price of researching, developing, and implementing analytics.

The theme of alienation was related to affect and dealt with a set of strong emotional reactions to potential futures for learning analytics. These often made reference to Big Brother (Orwell, 1949) and to a lack of humanity. Some painted vivid pictures of a dystopian future like this one:

I might be an alarmist, but there is too much at stake: from developing an underclass of limited-dimension robiticized learners, to propaganda-fed righteous fanatics, an automated, corrupted learning environment puts us on a path to an Orwellian future. [6616]

Such references to an Orwellian future also linked the themes of power and privacy. Boundaries around personal and private data are social agreements that depend on the social settings in which the data are created and shared (Hoel \& Chen, 2016). Shifts in power relations within society or within a specific context therefore have a direct bearing on privacy and on who can access and control learner data. The theme of privacy was closely related to power, ethics, and regulation and covered similar areas.

\section{Discussion}

This study addressed the following question: "What are the main factors that must be taken into account when implementing learning analytics during the coming decade?" The analysis of responses identified seven factors: pedagogy, complexity, ethics, power, regulation, validity, and affect.

The concerns and issues raised by the expert respondents in relation to these factors demonstrate that learning analytics is not solely the concern of specific sets of stakeholders, such as learners, educators, researchers, and developers. Instead, these factors are played out at different levels: political, social, and practical. This has been reflected in literature dealing with the implementation of learning analytics (Ferguson et al., 2015; Macfadyen \& Dawson, 2012). This study shows that these different levels need to be taken into account at every stage of the learning analytics process.

At the political level sit a series of important questions that relate to power and to pedagogy. What is the purpose of education? How do we know that learning has taken place? Who sets goals for learners and teachers? Who should control data 
related to learning and teaching? The expert responses show that these are disputed issues and that their responses depend on context. Viewed on the grand scale, education can be about growth, justice, and the development of society. Viewed from the classroom, the proxy measures of learning — tests, targets, and assessment - may appear to be what education is all about.

As Knight and his colleagues observed in their study of the theoretical foundations of learning analytics, these questions are inevitably bound up with epistemology (the nature of knowledge) and pedagogy (the nature of learning and teaching) (Knight, Buckingham Shum, \& Littleton, 2014). The current study makes it clear that the learning analytics community needs to keep both views in mind as it develops its research agenda. It is the proxy measures of learning that provide the data that fuel the analytics, but both proxies and analytics are simply tools that can support the development of both individuals and society.

The broad questions about education and learning also have other, less pleasant, answers that are reflected in the dystopian futures described by some expert respondents. Education can be a means of control, a way of classifying and stratifying society. Personal data are a valuable commodity that can be appropriated by those with power and sold to the highest bidder. These issues are only now beginning to emerge in the learning analytics literature (Dringus, 2012), which previously focused more on issues of privacy in a local context (Drachsler \& Greller, 2012; Prinsloo \& Slade, 2013).

Our study shows that the field of learning analytics will need to pay close attention to these issues of pedagogy and power and must engage with the development of policy in these areas. Ways of emphasizing the importance of pedagogy include making specific reference to it in calls for journal and conference papers, encouraging reviewers and editors to take this aspect of papers into account, covering this area in courses and training relating to learning analytics, looking out for speakers and keynotes who are clear about the pedagogy underpinning their work, and modelling good practice in this area. The field of learning analytics already includes many experts in pedagogy. When it comes to issues of power, important relevant expertise currently sits outside the field, in areas such as philosophy and social science. The LAK ' 18 conference made a move to open up this area for discussion by inviting Neil Selwyn, expert in the sociology of technology use in educational settings, as a keynote speaker. His talk on "The Promises and Problems of Learning Analytics" opened up a discussion within the community, which has been continued and amplified by this journal in an Invited Dialogue Special Section in the current issue (Essa, 2019; Ferguson, 2019; Prinsloo, 2019; Rosé, 2019; Selwyn, 2019).

It will also be important for the learning analytics community to engage with factors at the social level, the level at which we work and learn together in daily life. Learning analytics are complex, and one of these complexities concerns the number and variety of stakeholders. Respondents suggested that reflective communities and widespread alliances should be formed in the context of learning analytics. Such groupings would have an important role in relation to the factor of affect. Learning analytics need to take into account what it is that engages and motivates learners and teachers, and so engagement with these learners and teachers at every stage of the process will be valuable.

There is also a need to reduce the feelings of discomfort and unease about analytics. In the past, these have been expressed by stakeholder groups (Drachsler \& Greller, 2012). Our research shows that these concerns are shared by experts in the field. Bringing people together to engage with and understand the issues will be one way of addressing this problem. Several universities have working groups that deal with learning analytics, or communities of practice that share and develop relevant knowledge. However, as the special section of this journal earlier this year, on human-centred learning analytics, demonstrated, it is still rare to involve educators throughout the process of developing and implementing learning analytics, and even rarer to involve the learners who will be end users, except as participants in trials. The paper that introduced that special section outlines how learning analytics as a field could benefit from adopting a more human-centred approach that takes full account of critical stakeholders and their needs, desires, and experiences (Buckingham Shum et al., 2019).

Work at the social level will also be needed to unravel ethical issues and to develop regulations relating to data protection, data storage, and data standards. Some of this will be done at a national political level, but it is at the social level that it will be put into practice. Initial work in this area has shown that it is crucial to address both benefits and potential pitfalls from the perspectives of all key stakeholders (Slade \& Prinsloo, 2015). Our research shows that, as analytics are increasingly commonly used, it will be important for different communities to discuss and understand the value of their personal data and to know how they can be used, developed, and protected.

Many different stakeholders are involved with learning analytics at some level, but it is researchers and developers who work in this field on a day-to-day basis and have to deal with issues at the practical level. At this level, a fundamental concern for the field is validity. This is an issue at several levels, the first of which is whether the promise of learning analytics can be shown to be sound in practice, resulting in "real large-scale benefits to learners or institutions" [2775]. This concern encompasses many finer-grained issues, including whether and how it is possible to measure internal factors, such as learner motivation. There have been reports of promising early results (Arnold \& Pistilli, 2012; Sclater \& Mullan, 2017), but commercially sensitive results from the for-profit sector remain unpublished. Our research shows that the evidence that learning 
analytics delivers benefits is not yet convincing to the experts in the field. Much more technical and research work is required, which is challenging but achievable.

There are several other issues related to the validity of learning analytics. Most of these relate to training, to awareness of the work of others, and to the development of good practice. Individuals need to build on previous work in a variety of different fields, apply an appropriate conceptual framework, use an appropriate scientific method, and relate their work to pedagogic understanding. They should select and represent data carefully, be aware of gaps or distortions in their data, and take context into account. When publicizing or marketing their tools, they should avoid hype, misrepresentations, and conflicts of interest.

Other issues concerning validity relate to the other day-to-day users of learning analytics: learners and educators. They should not have to take the analytics on trust but should have opportunities to check their validity. It should therefore be possible to interrogate the data and to check the algorithms and the assumptions on which they are based. Some training will be required to do this effectively and to develop and inform practice, so analytics need to become part of the curriculum for students and an element of continuing professional development for teachers.

A limitation of the current research is that the focus on expert knowledge excludes the voice of the end users of learning analytics: students and other learners. This does not reduce the validity of the findings, but it means that an important perspective is missing - a perspective with the potential to shift the relative importance of the thematic categories and introduce other ideas. As suggested above, work needs to be done to increase learners' expertise in the use and implications of learning analytics.

\section{Conclusions}

Previous pedagogic futures reports have drawn on a narrower range of expert authors than this study and have not been peer reviewed as research outputs. This Policy Delphi study is the first to explore the future of learning analytics, drawing on the experience of a wide network of experts from around the world and using its findings to build on previous studies. Overall, this research found that experts in learning analytics are positive about the field's potential to improve or even transform learning, but they have significant concerns about the work needed to realize this potential. There are major technical challenges, and the experts are largely (but not wholly) confident that these can be overcome. There are wider social, political, and pedagogical issues to be tackled, and these are much more complex and difficult. On these issues, the experts are less confident of a successful resolution. Seven factors will have to be taken into account when implementing learning analytics during the coming decade: pedagogy, complexity, ethics, power, regulation, validity, and affect. In order to do this effectively, major investment of thoughtful effort will be required in terms of research agendas and funding, policy, and regulation and developing and informing practice among all those who engage with learning analytics.

\section{Declaration of Conflicting Interest}

The authors declared no potential conflicts of interest with respect to the research, authorship, and/or publication of this article.

\section{Funding}

The publication of this article received financial support from the European Commission Seventh Framework Programme, which funded the Learning Analytics Community Exchange (www.laceproject.eu): Grant number 619424.

\section{References}

Adams Becker, S., Freeman, A., Giesinger Hall, C., Cummins, M., \& Yuhnke, B. (2016). NMC/CoSN Horizon Report: 2016 K-12 Edition. Austin, TX: NMC. https://www.nmc.org/publication/nmc-cosn-horizon-report-2016-k-12-edition/.

ADL. (2018). An organized list of ADL's resources available on github. http://adlnet.github.io/.

ADL. (2017) xAPI-Spec. https://github.com/adlnet/xAPI-Spec.

Apereo. (2016). Apereo Open Analytics at a Glance. https://www .apereo.org/communities/learning-analytics-initiative/apereo-openanalytics-glance.

Arnold, K. E., \& Pistilli, M. (2012). Course Signals at Purdue: Using learning analytics to increase student success. Paper presented at LAK '12 (30 April-2 May), Vancouver, Canada. New York, USA: ACM. http://dx.doi.org/10.1145/2330601.2330666

Braun, V., \& Clarke, V. (2006). Using thematic analysis in psychology. Qualitative Research in Psychology, 3, 77-101. http://dx.doi.org/10.1191/1478088706qp063oa

Buckingham Shum, S., Ferguson, R., \& Martinez-Maldonado, R. (2019). Human-centred learning analytics. Journal of Learning Analytics, 6(2), 1-9. https://doi.org/10.18608/jla.2019.62.1

Campbell, J. P., DeBlois, P. B., \& Oblinger, D. G. (2007). Academic analytics: a new tool for a new era. Educause Review, $42(4), 40-57$. https://er.educause .edu/articles/2007/7/academic-analytics-a-new-tool-for-a-new-era

Clow, D., Cross, S., Ferguson, R. and Rienties, B. (2014). Evidence Hub Review. Milton Keynes: LACE Project. 
http://www.laceproject.eu/deliverables/d2-5-evidence-hub/

Cohen, J. (1960). A coefficient of agreement for nominal scales. Educational and Psychological Measurement, XX(1), 37-46. https://doi.org/10.1177/001316446002000104

Cormack, A. (2016). A data protection framework for learning analytics. Journal of Learning Analytics, 3(1), 91-106. https://doi.org/10.18608/jla.2016.31.6

Dalkey, N. C. (1969). The Delphi Method: An Experimental Study of Group Opinion. Santa Monica, CA: Rand Corporation. https://www.rand.org/pubs/research memoranda/RM5888.html.

Dawson, S., Gašević, D., Siemens, G., \& Joksimovic, S. (2014). Current state and future trends: A citation network analysis of the learning analytics field. Paper presented at LAK '14 (24-28 March), Indianapolis, IN. New York, USA: ACM. http://dx.doi.org/2567574.2567585

Drachsler, H., \& Greller, W. (2012). The pulse of learning analytics: Understandings and expectations from stakeholders. Paper presented at LAK '12 (29 April-2 May, 2012), Vancouver, Canada. New York, USA: ACM. http://dx.doi.org/10.1145/2330601.2330634

Drachsler, H., \& Greller, W. (2016). Privacy and analytics: It's a DELICATE issue. A checklist for trusted learning analytics. Paper presented at LAK '16 (25-29 April, 2016), Edinburgh, UK. New York, USA: ACM. http://dx.doi.org/10.1145/2883851.2883893

Dringus, L. P. (2012). Learning analytics considered harmful. Journal of Asynchronous Learning Networks, 16(3), 87-100.

Engelfriet, A., Manderveld, J., \& Jeunink, E. (2017). Learning Analytics Under the Dutch Data Protection Act. SURFnet. https://www.surf.nl/handreiking-learning-analytics-onder-de-wet-bescherming-persoonsgegevens

Essa, A. (2019) Is data dark? Lessons from Borges's 'Funes the Memorius'. Journal of Learning Analytics, 6(3), 35-42. http://dx.doi.org/10.18608/jla.2019.63.7

European Parliament and Council. (2016). Regulation (EU) 2016/679 of the European Parliament and of the Council of 27 April 2016 on the Protection of Natural Persons with Regard to the Processing of Personal Data and on the Free Movement of Such Data. http://eur-lex.europa.eu/legal-content/EN/TXT/?uri=CELEX\%3A32016R0679.

Ferguson, R. (2012). Learning analytics: Drivers, developments and challenges. International Journal of Technology Enhanced Learning (IJTEL), 4(5/6), 304-317.

Ferguson, R. (2019). Ethical challenges for learning analytics. Journal of Learning Analytics, 6(3), 25-30. http://dx.doi.org/10.18608/jla.2019.63.5

Ferguson, R., Brasher, A., Clow, D., Cooper, A., Hillaire, G., Mittelmeier, J., Rienties, B., Ullmann, T., \& Vuorikari, R. (2016). Research evidence on the use of learning analytics: Implications for education policy - Study. Joint Research Centre Science for Policy Report. Seville, Spain: EUR 28294. http://dx.doi.org/10.2791/955210

Ferguson, R., Cooper, A., Drachsler, H., Kismihok, G., Boyer, A., Tammets, K., \& Martinez Mones, A. (2015). Learning analytics: European perspectives. Paper presented at LAK '15 (16-20 March, 2015), Poughkeepsie, NY, USA. New York, USA: ACM. http://dx.doi.org/10.1145/2723576.2723637

Ferguson, R., Hoel, T., Scheffel, M., \& Drachsler, H. (2016). Guest editorial: Ethics and privacy in learning analytics. Journal of Learning Analytics, 3(1), 5-15. https://doi.org/10.18608/jla.2016.31.2

Ferguson, R., Macfadyen, L. P., Clow, D., Tynan, B., Alexander, S., \& Dawson, S. (2015). Setting learning analytics in context: Overcoming the barriers to large-scale adoption. Journal of Learning Analytics, 1(3), 120-144. https://doi.org/10.18608/jla.2014.13.7

Goodyear, P., Banks, S., Hodgson, V., \& McConnell, D. (Eds.). (2004). Advances in Research on Networked Learning. Norwell, Massachusetts, USA: Kluwer Academic Publishers. http://dx.doi.org/10.1007/1-4020-7909-5

Griffiths, D., Brasher, A., Clow, D., Ferguson, R., \& Yuan, L. (2016). Visions of the future: Horizon report. http://www.laceproject.eu/deliverables/d3-2-visions-of-the-future-2/

Hernández Leo, D., Rodríguez-Triana, M., Inventado, P., Mor, Y. (Eds.). 2017. Special issue of IxD\&A Connecting Learning Design and Learning Analytics. http://ixdea.uniroma2.it/inevent/events/idea2010/index.php?s=10\&a=10\&link=ToC $33 \mathrm{P}$

Hoel, T., \& Chen, W. (2016). Privacy-driven design of learning analytics applications: exploring the design space of solutions for data sharing and interoperability. Journal of Learning Analytics, 3(1), 139-158.

Hoel, T., Griffiths, D., \& Chen, W. (2017). The influence of data protection and privacy frameworks on the design of learning analytics systems. Paper presented at LAK ’17, Vancouver, British Columbia, Canada. New York, USA: ACM. https://doi.org/10.1145/3027385.3027414

IMS Global Learning Consortium. (2018). Caliper Analytics Specification, version 1.1. https://www.imsglobal.org/sites/default/files/caliper/v1p1/caliper-spec-v1p1/caliper-spec-v1p1.html

Jisc. (n.d.). Learning Analytics. Harness the Power of Your Data. https://www.jisc.ac.uk/learning-analytics Jiscdev. (n.d.). Jisc Learning Analytics Statement Templates. https://github.com/jiscdev/xapi

Johnson, L., Adams Becker, S., Cummins, M., Estrada, V., Freeman, A., \& Hall, C. (2016). NMC Horizon Report: 2016 Higher Education Edition. Austin, Texas, USA: NMC. https://www.nmc.org/publication/nmc-horizon-report-2016-higher-education-edition/.

Knight, S., Buckingham Shum, S., \& Littleton, K. (2014). Epistemology, assessment, pedagogy: Where learning meets analytics in the middle space. Journal of Learning Analytics, 1(2), 23-47. https://doi.org/10.18608/jla.2014.12.3

Kurzweil, R. (2005). The Singularity Is Near. London, UK: Duckworth.

LACE. (n.d.). Ethics and Privacy in Learning Analytics. http://www.laceproject.eu/ethics-privacy-learning-analytics/ 
Landis, J. R., \& Koch, G. G. (1977). The measurement of observer agreement for categorical data. Biometrics, 33(1), 159-174. http://dx.doi.org/10.2307/2529310

Linstone, H. A., \& Turoff, M. (2002). The Delphi Method: Techniques and Applications. Boston, Massachusetts, USA: Addison-Wesley.

Long, P., \& Siemens, G. (2011). Penetrating the fog: Analytics in learning and education. Educause Review, 46(5), 31-40. https://er.educause.edu/articles/2011/9/penetrating-the-fog-analytics-in-learning-and-education

Macfadyen, L., \& Dawson, S. (2012). Numbers are not enough. Why e-learning analytics failed to inform an institutional strategic plan. Educational Technology \& Society, 15(3), 149-163. https://www.jstor.org/stable/jeductechsoci.15.3.149

Macfadyen, L., Dawson, S., Pardo, A., \& Gašević, D. (2014). Embracing Big Data in complex educational systems: The learning analytics imperative and the policy challenge. Research \& Practice in Assessment, 9(Winter), 17-28. https://eric.ed.gov/?id=EJ1062692

McIntosh, N. E. (1979). Barriers to implementing research in higher education. Studies in Higher Education, 4(1), 77-86. http://dx.doi.org/10.1080/03075077912331377121

National Academy of Education. (2017). Big Data in Educaton, Balancing the Benefits of Educational Research and Student Privacy. http://naeducation.org/wp-content/uploads/2017/05/NAEd BD Booklet FINAL 051717 3.pdf

Orwell, G. (1949). Nineteen Eighty-Four. London: Secker \& Warburg.

Perry, M. R., et al. (2018). SPEC Kit 360. https://publications.arl.org/Learning-Analytics-SPEC-Kit-360/.

Prinsloo, P. (2019). Commentary on Neil Selwyn's LAK18 keynote address. Journal of Learning Analytics, 6(3), 20-24. http://dx.doi.org/10.18608/jla.2019.63.4

Prinsloo, P., \& Slade, S. (2013). An evaluation of policy frameworks for addressing ethical considerations in learning analytics. Paper presented at LAK '13 (8-12 April 2013), Leuven, Belgium. New York, USA: ACM. http://dx.doi.org/10.1145/2460296.2460344

Prinsloo, P., \& Slade, S. (2017). Ethics and learning analytics: Charting the (un)charted. In Lang, C. et al. (Eds.), Handbook of Learning Analytics (pp. 49-57). SoLAR. https://doi.org/10.18608/hla17

Rosé, C. P. (2019). Monolith, multiplicity, or multivocality: What do we stand for and where do we go from here? Journal of Learning Analytics, 6(3), 31-34. http://dx.doi.org/10.18608/jla.2019.63.6

Sclater, N., \& Mullan, J. (2017). Learning Analytics and Student Success - Assessing the Evidence. Bristol, UK: Jisc. https://repository.jisc.ac.uk/6560/1/learning-analytics_and_student_success.pdf.

Selwyn, N. (2019). What's the problem with learning analytics? Journal of Learning Analytics, 6(3), 11-19. http://dx.doi.org/10.18608/jla.2019.63.3

Sharples, M. (2000). The design of personal mobile technologies for lifelong learning. Computers \& Education, 34(3-4), 177-193. https://dx.doi.org/10.1016/S0360-1315(99)00044-5

Sharples, M., de Roock, R., Ferguson, R., Gaved, M., Herodotou, C., Koh, E., Kukulska-Hulme, A., Looi, C-K., McAndrew, P., Rienties, B., Weller, M. \& Wong, L. H. (2016). Innovating Pedagogy 2016: Open University Innovation Report 5. Milton Keynes, UK: The Open University. https://iet.open.ac.uk/file/innovating pedagogy 2016.pdf.

Siemens, G. (2005). Connectivism: A learning theory for the digital age. International Journal of Instructional Technology and Distance Learning, 2(1).

Siemens, G., Gašević, D., Haythornthwaite, C., Dawson, S., Buckingham Shum, S., Ferguson, R., Duval, E., Verbert, K., \& Baker, R. S. J d. (2011). Open Learning Analytics: An Integrated and Modularized Platform (Concept Paper). https://solaresearch.org/core/openlearning-analytics-an-integrated-modularized-platform/

Slade, S., \& Prinsloo, P. (2015). Student perspectives on the use of their data: Between intrusion, surveillance and care. European Journal of Distance and E-learning, 18(1). http://www.eurodl.org/index.php?p=special\&sp=articles\&inum=6\&abstract=672\&article=679

Tsai, Y. S., Moreno-Marcos, P. M., Tammets, K., Kollom, K., \& Gašević, D. (2018, March). SHEILA policy framework: Informing institutional strategies and policy processes of learning analytics. In Proceedings of the 8th International Conference on Learning Analytics and Knowledge (pp. 320-329). ACM. http://dx.doi.org/10.1145/3170358.3170367

Turoff, M. (1970). The Design of a Policy Delphi, reprinted in The Science of Public Policy, vol. IV, Policy Analysis II (2002), T. Miyakawa (Ed.), pp. 488-517. https://dx.doi.org/10.1016/0040-1625(70)90161-7

Turoff, M. (2002). The Policy Delphi. In H. A. Linstone \& M. Turoff (Eds.), The Delphi Method: Techniques and Applications (pp. 8096). Boston, Massachusetts, USA: Addison-Wesley. 